\title{
Websocket untuk Optimasi Kecepatan Data Transfer pada Real Time Chatting
}

\author{
Asep Rizki Maulana ${ }^{1}$, Alam Rahmatulloh ${ }^{2}$ \\ 1,2 Teknik Informatika, Fakultas Teknik, Universitas Siliwangi, Indonesia \\ ${ }^{1}$ pedoelski@gmail.com,2alam@unsil.ac.id
}

\section{INFORMASI ARTIKEL}

\begin{tabular}{l} 
KATA KUNCI \\
\hline AJAX, \\
chatting, \\
long polling, \\
real time, \\
websocket
\end{tabular}

\section{KORESPONDENSI}

Telepon: +6285223519009

E-mail: alam@unsil.ac.id

\section{PENDAHULUAN}

Ditemukannya internet pada tahun 1969 oleh Depatemen Pertahanan Amerika telah merubah segala macam bentuk pengiriman pesan. Surat Elektronik (email) yang diperkenalkan oleh Raymon Samuel di era 1971 semakin membuat pengiriman pesan lebih efektif dan bisa menjawab kompleksitas dari materi pesan tersebut. Saat ini teknologi yang sedang tren adalah chatting, yaitu sebuah bentuk komunikasi secara langsung seperti bercakap cakap atau berkirim pesan secara real time menggunakan teks melalui jaringan internal, metode chatting dimulai dari synchronous sampai sekarang Asynchronous JavaScript and XML (AJAX).

Cara kerja $A J A X$ untuk membuat request ke server secara asynchronous atau tanpa melakukan refresh halaman website yaitu dengan menggunakan XML HTTP Request Object Javascript, kemudian web server akan merenspon dan mengirimkan hasilnya melalui web browser. Salah satu kekurangan dari $A J A X$ adalah beban dari HTTP header yang tidak efisien untuk pesan-pesan yang kecil.

\section{A B S T R A K}

Bentuk komunikasi yang sedang menjadi trending saat ini adalah bertukar pesan atau chatting. Chatting memanfaatkan teknologi berkirim pesan secara real time menggunakan teks melalui jaringan internal. Metode chatting dimulai dari synchronous sampai sekarang Asynchronous JavaScript and $X M L(A J A X)$. AJAX dapat menggunakan metode polling ataupun long polling. Metode long polling memiliki kekurangan karena melakukan proses request secara terus menerus. Jika banyak pengguna yang melakukan request dapat menyebabkan server menjadi sibuk dan down. Pada penelitian ini untuk mengatasi permasalahan tersebut akan dibuat aplikasi chatting dengan menggunakan komunikasi full-duplex dengan memanfaatkan teknologi web socket. Hasil percobaan pada penelitian menunjukan bahwa penggunaan web socket mampu mengurangi lalu lintas jaringan dan latency sehingga lebih baik dari metode AJAX. Nilai presentase transmit data dan receive data dari implementasi AJAX adalah 90,37\% dan 94,88\%. Setelah metode web socket diterapkan nilai presentase transmit data dan receive masing-masing lebih baik menjadi 9,63\% dan $5,12 \%$.
$A J A X$ sudah mampu menyajikan halaman web secara real-time, namun dengan metode long polling yang mengirimkan request secara terus menerus dikalikan jumlah pengguna yang banyak akan menimbulkan server sibuk bahkan down. Perkembangan teknologi yang sedang berkembang saat ini untuk komunikasi real time adalah Websocket. Websocket menggunakan komunikasi dua arah (full-duplex) melalui koneksi TCP tunggal [1].

Fokus penelitian ini adalah membandingkan kecepatan data transfer pada aplikasi chatting antara Websocket dan $A J A X$, untuk dijadikan perbandingan tercepat dan teroptimal diantara kedua teknologi tersebut.

\section{LANDASAN TEORI}

\subsection{Websocket}

Websocket adalah standar baru untuk komunikasi full-duplex (dua arah secara bersamaan) sehingga komunikasi yang terjadi antara client dan server lebih real-time [2]. 


\section{2. $A J A X$}

AJAX, singkatan dari "Asynchronous JavaScript and $X M L$ ", merupakan metode suatu laman web menggunakan Javascript agar dapat menerima konten yang di request tanpa harus malakukan refresh pada halaman tersebut. Metode yang dapat digunakan $A J A X$ adalah polling dan long polling [3].

\subsection{Long Polling}

Metode ini yang diantaranya digunakan oleh teknologi $A J A X$ dengan cara mengirimkan request secara terus menerus dari client ke server, hal tersebut menyebabkan server akan jadi sibuk dan rentan terkena serangan DDOS [4].

\subsection{Full Duplex}

Full Duplex adalah jenis komunikasi dua arah dimana kedua stasiun dapat melakukan transmisi secara simultan, keduanya bisa berkomunikasi, medium membawa dalam dua arah pada waktu yang sama [5].

\section{METODOLOGI}

Ada 5 tahapan dan metode yang akan di lakukan di antaranya: Pengumpulan Data, Perancangan, Implementasi, Pengujian dan Analisis yang dapat dilihat pada Gambar 1 .

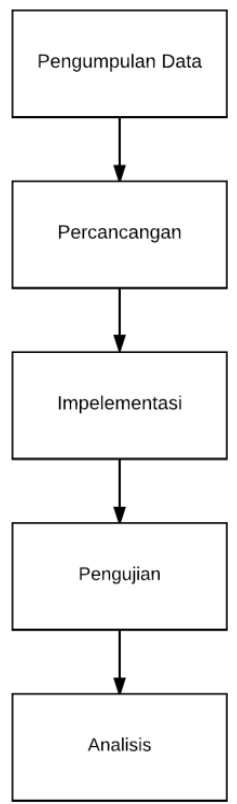

Gambar 1 Tahapan metodologi

\subsection{Pengumpulan Data}

Pengumpulan data dilakukan untuk mengumpulkan berbagai data dan informasi yang diperlukan dan berhubungan dengan penelitian. Tahapan-tahapan yang dilakukan pada pengumpulan data yaitu studi kepustakaan.

\subsection{Perancangan}

Tahapan perancangan yaitu pembuatan aplikasi yang akan dibuat, mulai dari kode websocket menggunakan php dan javascript, kode AJAX menggunakan PHP dan javascript dengan terintegrasi pada database, beserta hasil pembuatan aplikasinya.

\section{Perancangan Websocket}

Merancang sebuah sistem chatting sederhana menggunakan teknologi websocket dan PHP, keseluruhan kode Websocket terdiri dari beberapa metode dan event. Gambar 2 adalah source code perancangan koneksi websocket.

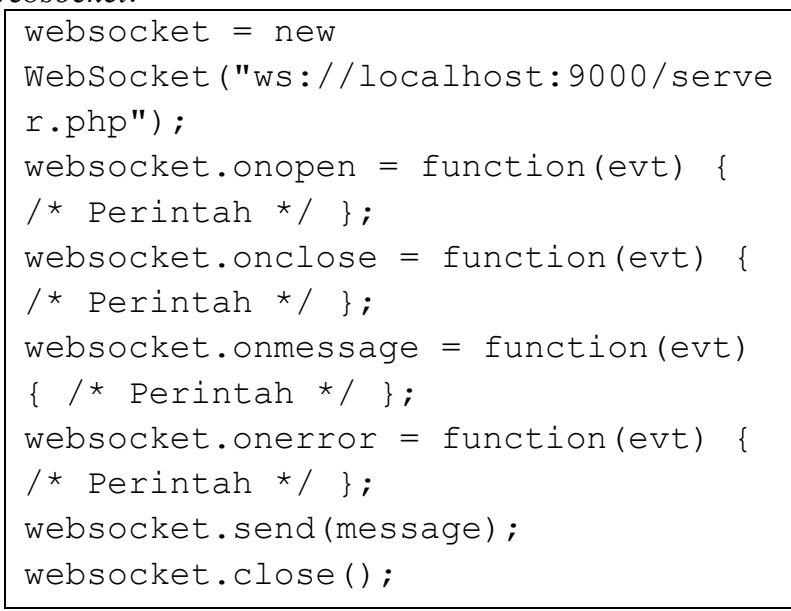

Gambar 2 Koneksi Websocket

Untuk membuka koneksi socket cukup memanggil New Websocket(ws://SERVER URL), karena websocket menggunakan protokol yang berbeda untuk koneksi ws:// daripada $h t t p: / /$ dan di ikuti oleh host, nomor port, dan script server.php, dengan skema koneksi websocket yang dapat dilihat pada gambar 3 .

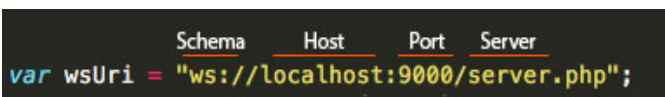

Gambar 3 Skema Pembuatan Koneksi WebSocket

Tepat setelah membuka koneksi perlu melampirkan beberapa event handler yang memberitahu tentang status konektivitas, kesalahan dan pesan masuk. Pembuatan aplikasi chatting websocket digabungkan dengan library ajax. Tahap berikutnya membuat sebuah html dan tampilan css yang simple. WebSocket yang berjalan secara permanen atau realtime, melakukan handsaking websocket, mengirim atau menerima data dari halaman obrolan dan menangani banyak klien. Setelah handshaking, klien sekarang dapat mengirim dan menerima pesan namun, pesan yang dikirim semuanya terenkripsi, dengan perintah php server.php maka, server berjalan dengan baik seperti gambar 4 .

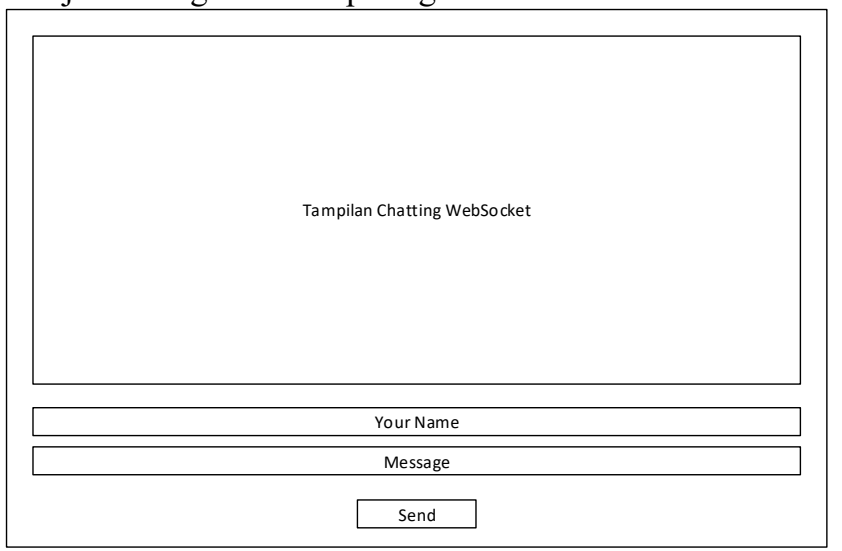

Gambar 4 Interface Chatting Websocket 


\section{Perancangan $A J A X$}

Teknologi ajax dalam chatting biasanya menggunakan setInterval() dari JQuery sehingga program akan me-refresh obrolan setiap milidetik, memuat data dari database yang dikembalikan ke dalam element, memperbarui shout-box dengan pesan baru yang ditambahkan.

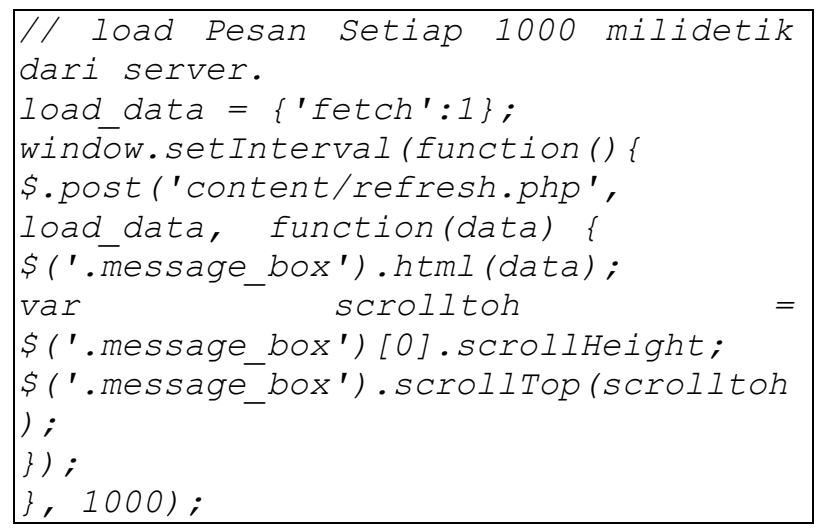

Gambar 5 Perancangan interval Ajax

Perancangan interval AJAX dapat dilihat pada Gambar 5 sedangkan rancangan tampilan aplikasi chatting dapat dilihat pada Gambar 6.

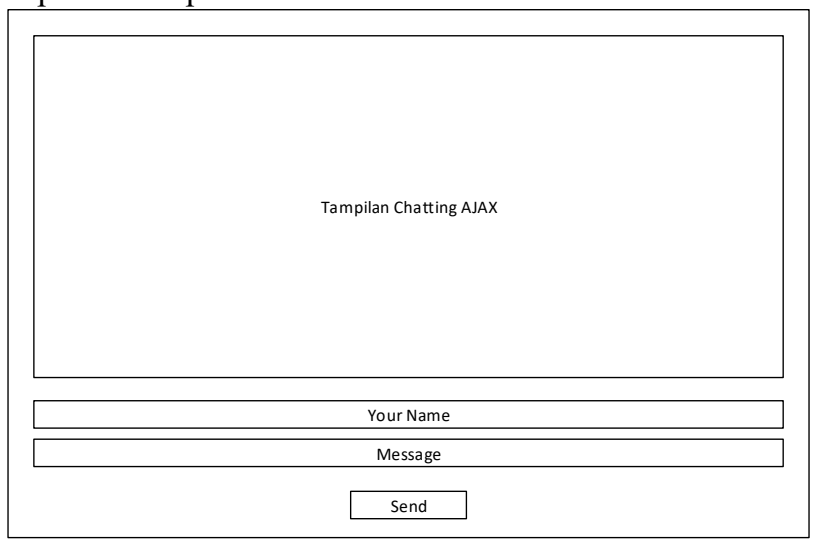

Gambar 6 Interface Chatting Ajax

\subsection{Implementasi}

Tahapan implementasi yaitu tahapan memasukan aplikasi chatting websocket dan AJAX yang sudah di rancang pada server dan installasi docker pada server dengan container cadvisor, grafana, prometheus dan debian sehingga bisa membandingkan aplikasi chatting mana yang lebih baik dalam segi kecepatan.

\subsection{Pengujian}

Tahapan pengujian akan dilakukan pada aplikasi chatting dengan menggunakan Mozilla Firefox selama 30 menit dengan perbandingan antara aplikasi chatting websocket dan ajax secara bersamaan dengan 4 user.

\subsection{Analisis}

Tahapan analisis yaitu membandingkan aplikasi chatting menggunakan $A J A X$ dengan aplikasi chatting menggunakan websocket menggunakan container cadvisor, promethius, dan grafana dari aplikasi server docker dengan melihat kecepatan pengiriman, membandingkan penggunaan bandwidth pada websocket dan $A J A X$, membandingkan kinerja websocket dengan $A J A X$. Hasil dari perbandingan yang dilakukan adalah menentukan aplikasi yang paling lebih cepat dalam pengiriman pesan dan hemat dalam penggunaan bandwith.

\section{HASIL DAN PEMBAHASAN}

\subsection{Implementasi}

Tahapan implementasi penulis menjelaskan installasi menggunakan aplikasi virtualisasi modern pada server centos 7 yaitu menggunakan docker yang didalamnya terinstall container cadvisor, grafana, prometheus dan container opriting system debian jessie yang sudah terinstall untuk kebutuhan aplikasi chatting dengan teknologi websocket maupun ajax di dalam container tersebut berjalan sesuai yang diharapkan sehingga dapat membandingan tekonologi ajax dan websocket dalam segi kecepatan maupun penggunaan memory CPU, berikut tahapan installasi dan penerapannya.

\section{Install Docker}

Install docker pada centos 7 dengan perintah curl fsSL https://get.docker.com/|sh.

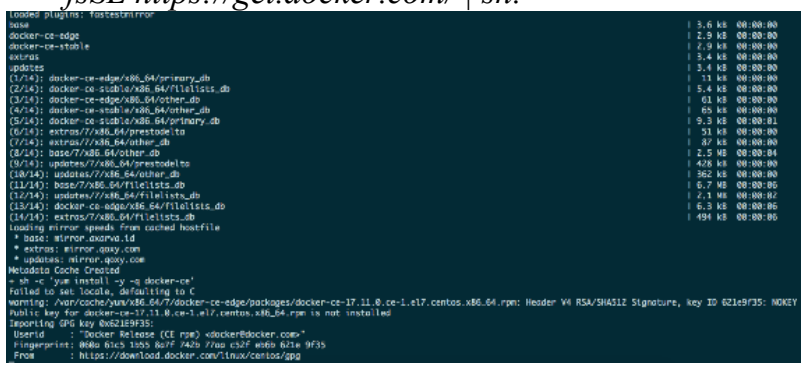

Gambar 7 Installasi Docker Engine

2. Install Container Debian untuk WebSocket

Menjalankan aplikasi websocket dengan perintah $p h p$

- q server.php di container debian

...calhost: /websocket - ssh root@192.168.1.100

root@137dba70276f:/www\# ls
index.php jquery-3.1.1.js server.php

root@137dba70276f:/www\# php -q server.php

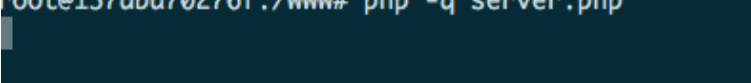

Gambar 8 Menjalankan websocket

Hasil dari menerapkan teknologi weboscket chatting dengan container debian jessie yang sedang berjalan bisa di lihat di gambar 9.

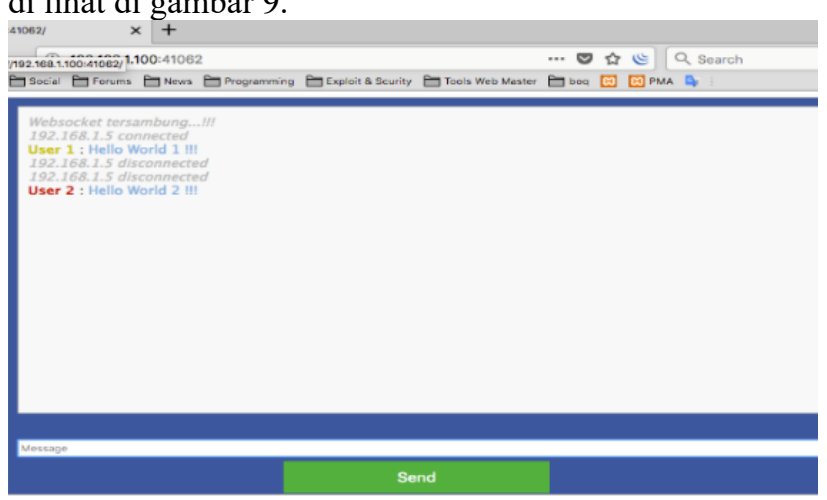

Gambar 9 Mengirim aplikasi websocket ke server 
3. Install Container Debian untuk AJAX

Membuat sebuah container debian (Gambar 10) dengan perintah docker run --name Ajax -p 41063:22 -p 41064:80-d-v /ajax:/www tomsik68/xampp

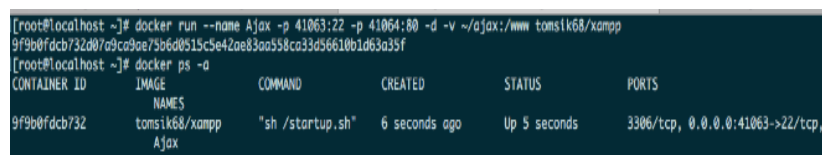

Gambar 10 Membuat Container debian

4. Install Container Cadvisor, Prometheus Dan Grafana

Install docker-compose dengan masuk ke dalam folder Prometheus lalu mengetikan perintah docker-

\section{compose up.}

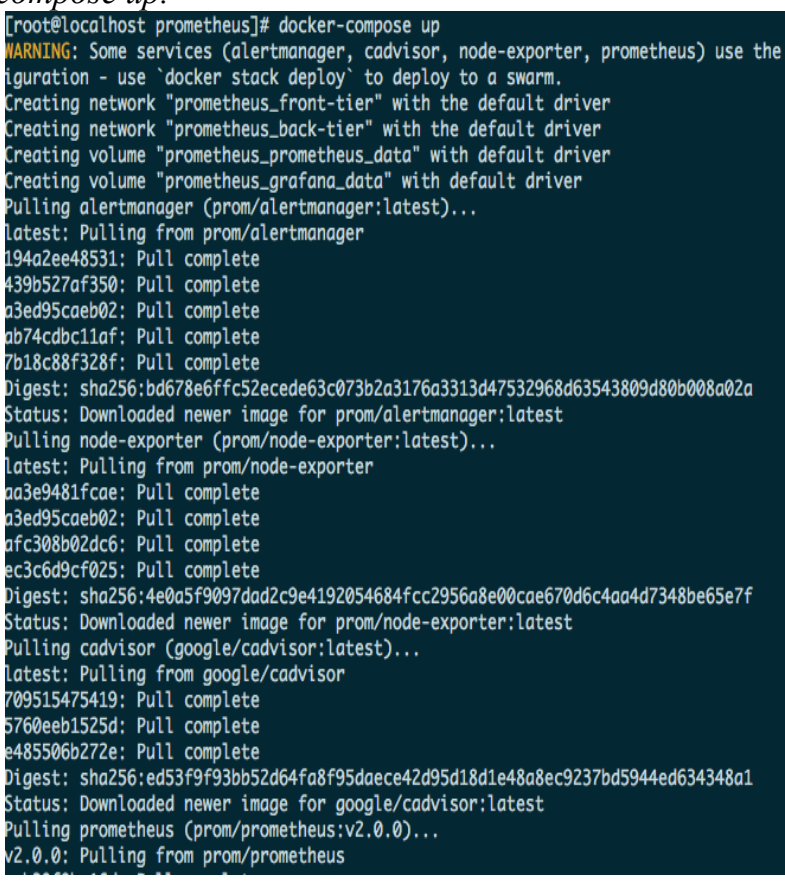

Gambar 11 Mendownload image cadvisor, Prometheus dan grafana

\subsection{Pengujian}

Tahapan pengujian akan dilakukan pada aplikasi chatting dengan menggunakan Mozilla Firefox selama 30 menit dengan perbandingan antara aplikasi chatting websocket dan ajax secara bersamaan dengan 4 user. 2 user aplikasi chatting dengan websocket, 2 user aplikasi chatting dengan ajax selama 30 menit, dengan tujuan akhir membandingkan aplikasi mana yang lebih baik diantara keduanya dan dapat dilihat pada gambar 12 dan 13.

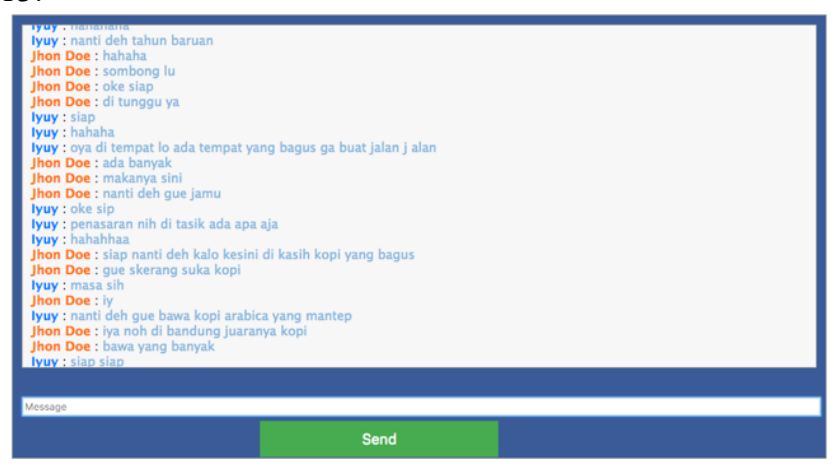

Gambar 12 Aktifitas chatting websocket saat di bandingkan 10 Asep Rizki Maulana

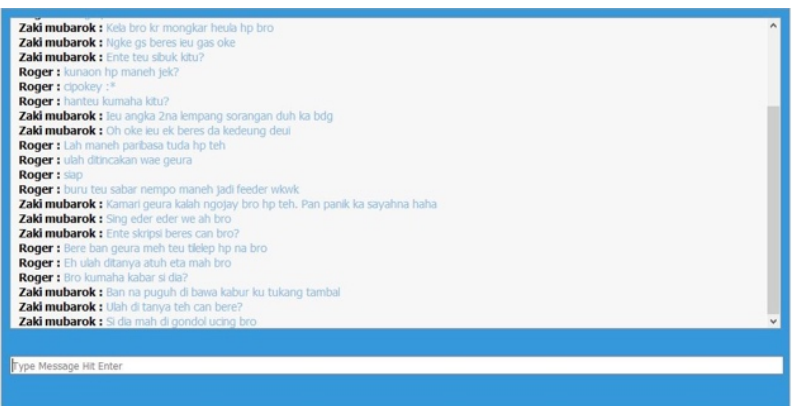

Gambar 13 Aktifitas chatting ajax saat di bandingkan

\subsection{Analisis}

Tahapan analisis ini menjelaskan perbandingkan dari websocket dengan ajax pada transmit data network dan receive data network, hasil dari chatting pada tahapan pengujian bisa dilihat pada tabel 1 .

\begin{tabular}{|c|c|c|}
\hline $\begin{array}{c}\text { Menit/ } \\
\text { Percobaan }\end{array}$ & Ajax & Websocket \\
\hline 1 & $246 \mathrm{~Kb}$ & $19 \mathrm{~Kb}$ \\
\hline 2 & $312 \mathrm{~Kb}$ & $116 \mathrm{~Kb}$ \\
\hline 3 & $473 \mathrm{~Kb}$ & $207 \mathrm{~KB}$ \\
\hline 4 & $553 \mathrm{~Kb}$ & $210 \mathrm{~Kb}$ \\
\hline 5 & $635 \mathrm{~Kb}$ & $214 \mathrm{~Kb}$ \\
\hline 6 & $724 \mathrm{~Kb}$ & $215 \mathrm{~Kb}$ \\
\hline 7 & $811 \mathrm{~Kb}$ & $216 \mathrm{~Kb}$ \\
\hline 8 & $917 \mathrm{~Kb}$ & $218 \mathrm{~Kb}$ \\
\hline 9 & $1.023 \mathrm{Mb}$ & $219 \mathrm{~Kb}$ \\
\hline 10 & $1.138 \mathrm{Mb}$ & $221 \mathrm{~Kb}$ \\
\hline 11 & $1.261 \mathrm{Mb}$ & $224 \mathrm{~Kb}$ \\
\hline 12 & $1.392 \mathrm{Mb}$ & $225 \mathrm{~Kb}$ \\
\hline 13 & $1.540 \mathrm{Mb}$ & $228 \mathrm{~Kb}$ \\
\hline 14 & $1.681 \mathrm{Mb}$ & $231 \mathrm{~Kb}$ \\
\hline 15 & $1.834 \mathrm{Mb}$ & $231 \mathrm{~Kb}$ \\
\hline 16 & $1.998 \mathrm{Mb}$ & $233 \mathrm{~Kb}$ \\
\hline 17 & $2.164 \mathrm{Mb}$ & $236 \mathrm{~Kb}$ \\
\hline 18 & $2.344 \mathrm{Mb}$ & $238 \mathrm{~Kb}$ \\
\hline 19 & $2.529 \mathrm{Mb}$ & $241 \mathrm{~Kb}$ \\
\hline 20 & $2.708 \mathrm{Mb}$ & $242 \mathrm{~Kb}$ \\
\hline 21 & $2.884 \mathrm{Mb}$ & $245 \mathrm{~Kb}$ \\
\hline 22 & $3.076 \mathrm{Mb}$ & $247 \mathrm{~Kb}$ \\
\hline 23 & $3.269 \mathrm{Mb}$ & $248 \mathrm{~Kb}$ \\
\hline 24 & $3.465 \mathrm{Mb}$ & $249 \mathrm{~Kb}$ \\
\hline 25 & $3.671 \mathrm{Mb}$ & $252 \mathrm{~Kb}$ \\
\hline 26 & $3.885 \mathrm{Mb}$ & $252 \mathrm{~Kb}$ \\
\hline 27 & $4.106 \mathrm{Mb}$ & $254 \mathrm{~Kb}$ \\
\hline 28 & $4.337 \mathrm{Mb}$ & $255 \mathrm{~Kb}$ \\
\hline 29 & $4.632 \mathrm{Mb}$ & $257 \mathrm{~Kb}$ \\
\hline 30 & $4.887 \mathrm{Mb}$ & $258 \mathrm{~Kb}$ \\
\hline Rata-rata & $2.04 \mathrm{Mb}$ & $217 \mathrm{~Kb}$ \\
\hline Total & $124.19 \mathrm{Mb}$ & $13.23 \mathrm{Mb}$ \\
\hline
\end{tabular}

Pada tabel 1 diatas hasil persentase dari transmit data network ajax adalah 90,37\% dan sementara hasil persentase websocket adalah 9,63\%. Sehingga dari data yang telah dibandingkan, websocket lebih efisien dalam penggunaan transmit data network daripada ajax. 
TABel 2. ReCeive Data Network

\begin{tabular}{|c|c|c|}
\hline $\begin{array}{c}\text { Menit/ } \\
\text { Percobaan }\end{array}$ & $\mathbf{A j a x}$ & Websocket \\
\hline 1 & $161 \mathrm{~Kb}$ & $39 \mathrm{~Kb}$ \\
\hline 2 & $206 \mathrm{~Kb}$ & $41 \mathrm{~Kb}$ \\
\hline 3 & $299 \mathrm{~Kb}$ & $50 \mathrm{~KB}$ \\
\hline 4 & $384 \mathrm{~Kb}$ & $53 \mathrm{~Kb}$ \\
\hline 5 & $463 \mathrm{~Kb}$ & $56 \mathrm{~Kb}$ \\
\hline 6 & $543 \mathrm{~Kb}$ & $57 \mathrm{~Kb}$ \\
\hline 7 & $618 \mathrm{~Kb}$ & $58 \mathrm{~Kb}$ \\
\hline 8 & $701 \mathrm{~Kb}$ & $60 \mathrm{~Kb}$ \\
\hline 9 & $783 \mathrm{~Kb}$ & $61 \mathrm{~Kb}$ \\
\hline 10 & $866 \mathrm{~Kb}$ & $62 \mathrm{~Kb}$ \\
\hline 11 & $949 \mathrm{~Kb}$ & $64 \mathrm{~Kb}$ \\
\hline 12 & $1.034 \mathrm{Mb}$ & $66 \mathrm{~Kb}$ \\
\hline 13 & $1.121 \mathrm{Mb}$ & $68 \mathrm{~Kb}$ \\
\hline 14 & $1.200 \mathrm{Mb}$ & $71 \mathrm{~Kb}$ \\
\hline 15 & $1.283 \mathrm{Mb}$ & $71 \mathrm{~Kb}$ \\
\hline 16 & $1.370 \mathrm{Mb}$ & $72 \mathrm{~Kb}$ \\
\hline 17 & $1.457 \mathrm{Mb}$ & $75 \mathrm{~Kb}$ \\
\hline 18 & $1.542 \mathrm{Mb}$ & $77 \mathrm{~Kb}$ \\
\hline 19 & $1.628 \mathrm{Mb}$ & $79 \mathrm{~Kb}$ \\
\hline 20 & $1.719 \mathrm{Mb}$ & $80 \mathrm{~Kb}$ \\
\hline 21 & $1.797 \mathrm{Mb}$ & $83 \mathrm{~Kb}$ \\
\hline 22 & $1.882 \mathrm{Mb}$ & $85 \mathrm{~Kb}$ \\
\hline 23 & $1.971 \mathrm{Mb}$ & $86 \mathrm{~Kb}$ \\
\hline 24 & $2.057 \mathrm{Mb}$ & $87 \mathrm{~Kb}$ \\
\hline 25 & $2.103 \mathrm{Mb}$ & $89 \mathrm{~Kb}$ \\
\hline 26 & $2.280 \mathrm{Mb}$ & $90 \mathrm{~Kb}$ \\
\hline 27 & $2.327 \mathrm{Mb}$ & $91 \mathrm{~Kb}$ \\
\hline 28 & $2.417 \mathrm{Mb}$ & $92 \mathrm{~Kb}$ \\
\hline 29 & $2.511 \mathrm{Mb}$ & $94 \mathrm{~Kb}$ \\
\hline 30 & $2.595 \mathrm{Mb}$ & $94 \mathrm{~Kb}$ \\
\hline Rata-rata & $1.277 \mathrm{Mb}$ & $69 \mathrm{~Kb}$ \\
\hline Total & $77.903 \mathrm{Mb}$ & $4.201 \mathrm{Mb}$ \\
\hline
\end{tabular}

Pada tabel 2 diatas hasil persentase dari receive data network ajax adalah 94,88\% dan websocket 5,12\%, Hasil yang ditunjukkan dari docker grafana dapat dilihat pada gambar 14.

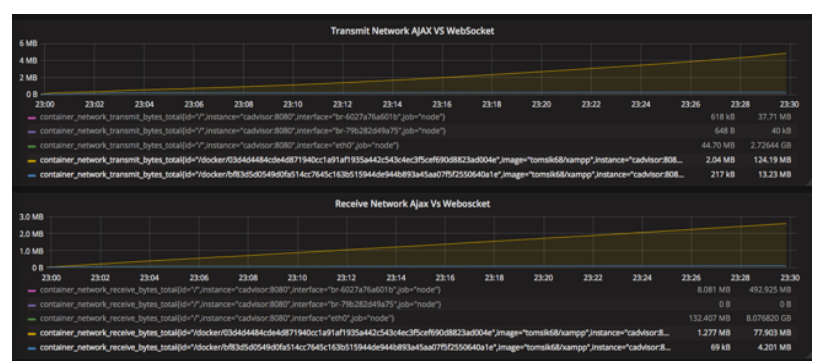

Gambar 14. Grafik docker Grafana

D. Kelebihan dan Kekurangan

Kelebihan pada sistem yang telah dibangun sebagai berikut:

1. Perbandingan ajax telah dilakukan dengan hasil persentase transmit data network $90,37 \%$ dan websocket $9,63 \%$ sementara persentase receive data network ajax 94,88\% dan websocket 5,12\%.
2. Websocket merupakan standar protokol jaringan yang dapat melayani standar protokol lain di atasnya

Kekurangan pada sistem yang telah dibangun: Data hasil dari docker grafana dan prometheus tidak seterusnya konsisten.

\section{KESIMPULAN}

1. Websocket dapat diimplementasikan pada aplikasi chatting dan mampu menghemat transmit data network serta receive data network dari ajax.

2. Telah berhasil menguji kecepatan transmit dan receive data network antara websocket dengan ajax dalam aplikasi chatting.

3. Perbandingan ajax telah dilakukan dengan hasil persentase transmit data network 90,37\% dan websocket $9,63 \%$ sementara persentase receive data network ajax 94,88\% dan websocket 5,12\% .

4. Weboscket secara teknis memungkinkan server untuk mendorong data kepada klien yang terhubung dengan protokol komunikasi dua arah yang dapat digunakan oleh browser dibandingkan dengan ajax di karnakan ajax mengambil data web secara background dan memperbarui isi sebagian halaman.

Sebaiknya dalam penelitian selanjutnya dilakukan dengan aplikasi perbadingan khusus untuk benchmark dan comparison baik di dalam lalu lintas latency maupun penggunaan memory dan CPU.

\section{DAFTAR PUSTAKA}

[1] H. Husen, A. Rahmatulloh and H. Sulastri, "Implementasi Komunikasi Full Duplex Menggunakan Sistem Informasi Pengelolaan Anggaran Universitas ABC," Simetris: Jurnal Teknik Mesin, Elektro dan Ilmu Komputer, vol. 9, no. 1, pp. 597-606, 142018.

[2] Q. Liu and X. Sun, "Research of Web Real-Time Communication Based on Web Socket," Int. J. Communications, Network and System Sciences, vol. 5, pp. 797-801, 2012.

[3] I. Hidayat, "Perbedaan Websocket dengan AJax," 512 $2015 . \quad$ [Online]. Available: http://izalhidayat.student.telkomuniversity.ac.id/perbeda an-websocket-dengan-ajax/. [Accessed 1912 2017].

[4] R. Appelqvist and O. Örnmyr, "Performance comparison of XHR polling, Long polling, Server sent events and Websockets," Performance comparison of XHR polling, Long polling, Server sent events and Websockets.

[5] T. C. SCIENCE, "Simplex, Half Duplex, Full Duplex," [Online]. Available: https://teachcomputerscience.com/simplex-half-duplexfull-duplex/. [Accessed 01 2018]. 


\section{BIODATA PENULIS}

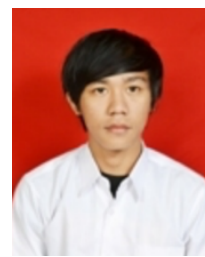

Asep Rizki Maulana

Mahasiswa Teknik Informatika, Fakultas

Teknik, Universitas Siliwangi. Selain

kegiatan dikampus berperan aktif juga dalam

komunitas web developer dan hacker Indonesia.

\section{Alam Rahmatulloh}

Dosen Teknik Informatika, Fakultas Teknik, Universitas Siliwangi, berperan aktif dalam bidang web, IoT, keamanan informasi, mobile dan android. 